\title{
Arquitetura cristã no Japão entre os séculos XVI e XIX
}

Joanes da Silva Rocha ${ }^{7}$

DOI 10.20396/eha.vil4.3423

Este ensaio tem por objetivo contextualizar a arquitetura cristã no Japão entre 1549, com a chegada dos primeiros europeus, até a construção das novas igrejas em 1873 com a reabertura política do Japão durante o governo Meiji. Para tal, o estudo foi divido em três partes: A primeira parte focando nas igrejas de traços nipônico e elementos portugueses da Companhia de Jesus que, infelizmente, hoje só podem ser acessadas por meio de documentação. Seguido de um hiato arquitetônico durante o fechamento do país pelo bakufu Tokugawa entre 1644 e 1873 no qual o cristianismo foi abolido e as igrejas destruídas. E, por último, o mencionado momento de renovação religiosa e construção de novas igrejas em estilo neogótico francês sobre orientação dos missionários europeus a partir de 1873 .

As primeiras igrejas (1549-1644)

Como apresentado por Arimura², as primeiras igrejas construídas pelos missionários portugueses a partir da chegada de Francisco Xavier em 1549 até a completa proibição das práticas cristãs pelo shogunato Tokugawa em 1644 é um assunto complexo e de difícil acesso, uma vez que todas as igrejas deste período foram destruídas. Como resultado, as únicas fontes disponíveis para estudo na atualidade são as descrições encontradas nas crônicas e manuscritos dos missionários e as representações pictóricas dos artistas japoneses nas telas dobráveis namban byōbu (南蛮屏風). Os Biombos namban.

Apesar das constantes cartas pedindo apoio para Europa, Goa e Macau, os recursos enviados para custear o trabalho missionário no Japão era escassos. Razão pela qual o apoio de alguns senhores locais que ser converteram ao cristianismo tornou-se crucial para a propagação da fé no arquipélago. Estes senhores locais, hoje chamados de Kirishitan daimyōs (吉利支丹大名), ou senho-

\footnotetext{
1 Mestre em Teoria e História da Arquitetura pela Universidade de Brasília, com intercambio em Kyōto, Japão. Bacharel em Arquitetura pela Uniplac e História pela Universidade de Brasília. Atualmente, é professor de Teoria e História da Arquitetura e pesquisador do Núcleo de Estudos Asiáticos da Universidade de Brasília (NEASIA-UnB) com ênfase na conservação do patrimonial mundial e presença lusitana no leste asiático (Japão e Macau). Também é historiador arquitetônico do ICOMOS-Brasil. E-mail: joanesrocha@gmail.com

2 ARIMURA, 2014, p. 53
} 
res cristãos, se tornaram os principais patronos das artes e arquitetura dos missionários no Japão. Pois, além de doar terrenos em suas províncias, eles também forneciam material e mão de obra construção de igrejas e colégios. ${ }^{3}$

Este primeiro período da atividade missionária é comumente dividido em dois momentos. Um primeiro estágio das atividades entre 1549-79 no qual as igrejas e colégios da Sociedade de Jesus era erguidas sobre antigas residências japonesa e templos budistas abandonados. ${ }^{4}$ E um segundo momento a partir de 1579 no qual buscava-se construir novas igrejas ao "Nostrus Modus" por influência do Visitador Geral da Índias Alessandro Valignano. Todavia, pesquisadores contemporâneos como Arimura, Diniz e Higashino, revelam que em virtude da escassez de recursos, foram poucas as igrejas efetivamente construídas inteiramente segundo o desejo de Valignano.

No entanto, é importante salientar que mesmo a prática de construídas igrejas católicas sobre antigos tempos budistas, especialmente de grupos religiosos menores como Hokkeshū, Jōdo Shinshū e Honganji, encontrou grande relutância por parte alguns padres e supervisores. Que diziam ser um sacrilégio e blasfêmia perante Deus. ${ }^{5}$ Contudo, estes terrenos abandonados como resultado das guerras internas do período Sengoku (1467-1573) eram os únicos terrenos suficientemente grandes e acessível financeiramente para a Companhia de Jesus.

E mesmo as igrejas construídas em terrenos neutros, como antigas residências ou espaços virgens, eram erguidas com madeira ao estilo local. Não só por uma questão de material disponível, mas, principalmente, para resistir aos terremotos e ventos fortes típicos da região. Um exemplo deste estilo arquitetônico foi a igreja de Arima, construída em 1581 com madeira reutilizada de diferentes templos budistas em layout de basílica composto por uma nave central e dois singelos corredores laterais.

Também há relatos de doação de tatames para os espaços de culto e, no caso da Igreja de Nossa Senhora da Assunção em Kyōto, as imagens existentes constantemente representam uma cruz de ouro no telhando. Como aparecem nos detalhes dos biombos de Kanō Naizen e Kanō Sōshū. [Figuras 01 e 02] A igreja de Nossa Senhora da Assunção em Kyōto foi construída em 1575 num pequeno espaço adquirido pelo padre Gaspar Vilela e em virtude do seu projeto com três pavimentos, atribuído à Organtino Grechi-Soldi, ficou conhecida pelos japoneses como Nanban-tera (南蛮寺). ${ }^{6}$

\footnotetext{
3 ELISONAS, 2006

4 Este fenômeno também pode ser observado na América Portuguesa ao transformar as conchas dos sambaquis em cal para pintura das igrejas e na América Espanhola quando os franciscanos adaptaram a residência cacique Maxixcatzin em Tlaxcala, México, em uma igreja no ano de 1524

5 DINIZ, 2001, p. 128

6 BITŌ, 2006; BOXER, 1986
} 

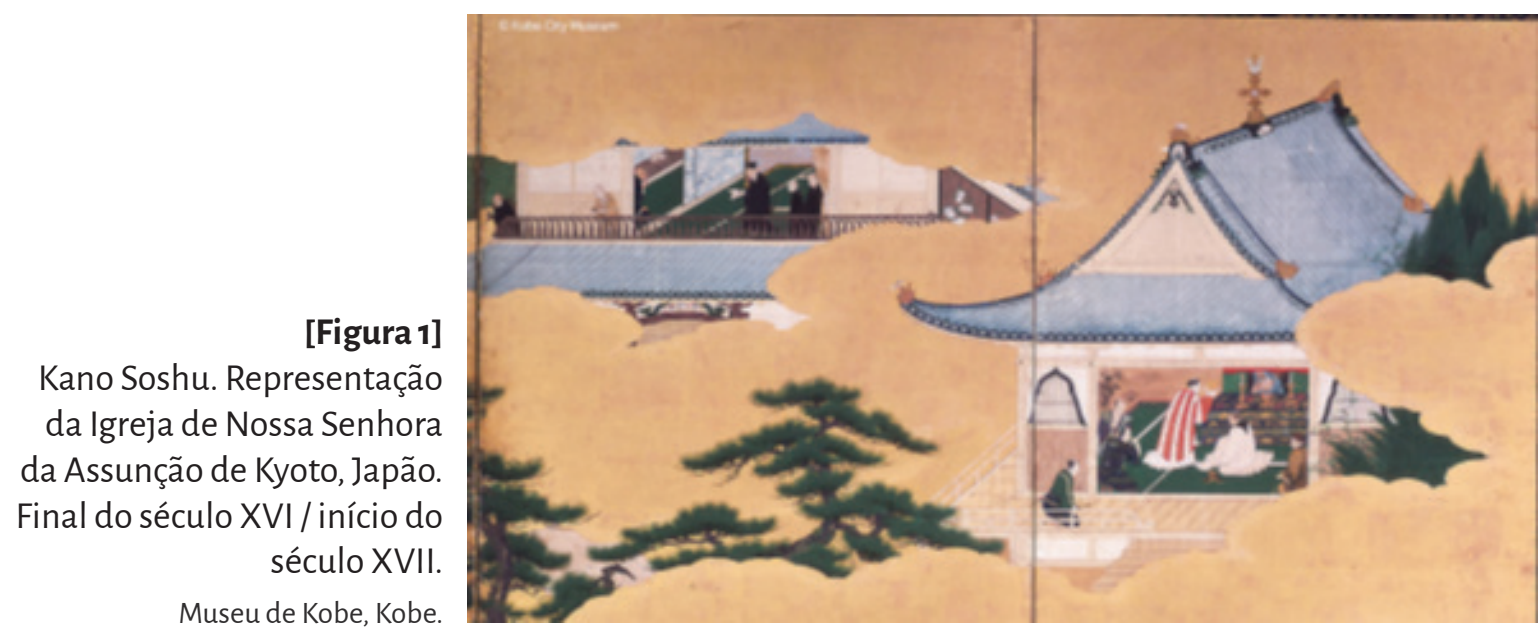

[Figura 2]

Kanō Naizen. Detalhe de uma igreja. Final do século XVI. O espaço é composto por dois edifícios, capela a direita e a sala de estudos a esquerda.

Museu de Kobe, Kobe.

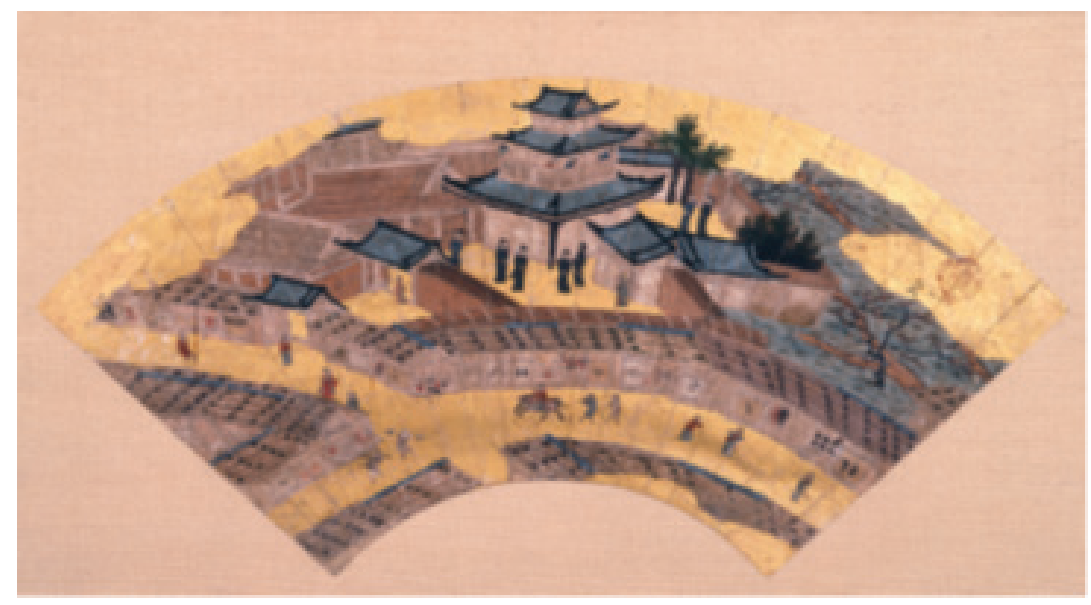

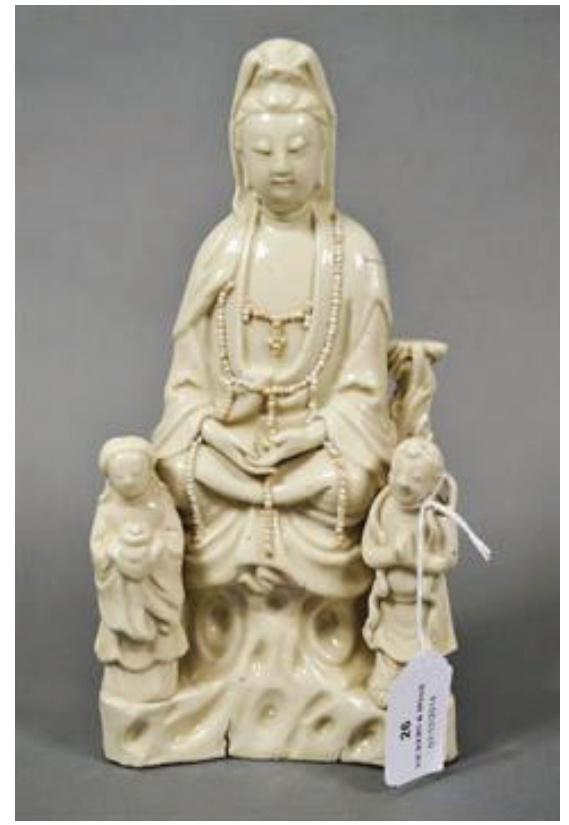

[Figura 3] Maria Kannon. Porcelana. Coleção Privada.

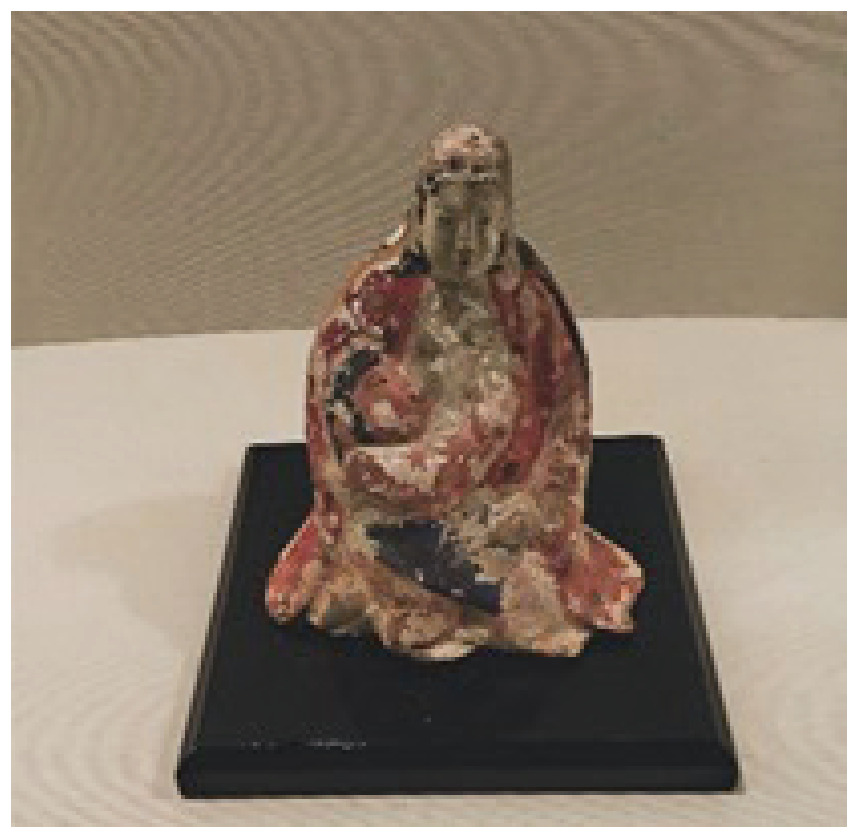

[Figura 4] Artefatos dos cristãos ocultos. Coleção Privada. 
O próprio Luis Frois, autor do clássico Historia de Japam, chamou a atenção para a altura do edifico e como ele destoava das edificações residenciais ao redor.

Todavia, a Igreja de Nossa Senhora da Assunção de Kyōto e tantas outras espalhadas pelo arquipélago, foram destruída a partir de 1587 por meio do decreto de expulsão de Toyotomi Hideyoshi chamado de Bateren tsuihourei (バテレン追放令).

A imaterialidade das igrejas (1644-1873)

Com a morte de Hideyoshi, Tokugawa leyasu garantiu seu domínio político sobre os outros senhores locais e apesar de ser receptivo ao comércio com Portugal e Espanha no início de sua regência, ele emitiu um decreto de proibição ao cristianismo em 1614 chamado Kirishitan kokugai tsuihōrei (キリシタン国外追放令) pelo qual visava eliminar a influência externa e construir uma nova ordem social baseado na divisão de classes sociais do confucionismo chinês conhecido como shinōkōsho (士農 工商). ${ }^{7}$ No qual a sociedade era dividida em quatro grupos: os samurais, os agricultores, os artesãos e os comerciantes.

Durante o período Tokugawa, ou Era Edo, houve intensa repressão ao cristianismo e todas as igrejas foram destruídas. Contudo, em algumas vilas na região de Omura e Coto, na atual prefeitura de Nagasaki, grupos de cristão japoneses mantiveram sua fé viva e em segredo por meio do culto familiar e pequenas confrarias. Eles são hoje denominados de cristãos ocultos ou senpuku kirishitan (潜伏キリシタン).

Em meados do século XVII, por ordem do shogunato, todas as famílias tiveram que participar de um senso por meio do registrou a um templo budista e, caso houvesse quaisquer relações com o cristianismo, deveriam declarar sua apostasia e de seus antepassados. ${ }^{8}$ Assim, para manter uma aparência de budistas perante a sociedade e evitar delações, os cristãos ocultos rezavam para estátuas budistas, tais como Kannon, tomando-a como uma representação da própria Virgem Maria. [figura 3] ${ }^{9}$

De tal modo, durante o período de proibição entre 1644-1873, ainda que não encontremos

7 Também conhecido como shiminbyōdō (四民平等).

8 Se o apóstata fosse homem, os registros contemplariam sete ou nove gerações; no caso de mulheres, quatro gerações. O registro era chamado de Terauke seido (制度請制度), ou sistema de garantia do templo. (MURAI, 2002; TAMAMURO, 2009) Eu desenvolve este tema mais afundo no texto: ROCHA, Joanes S. The triumph of perseverance: Kakure Kirishitan in Japan and its inscription on the world heritage list. Historical Yearbook, vol. XV, p. 161-173, 2018

9 SHEN, 2011, p. 40; SHIN, 2011, p. 4 
edifícios ou igrejas propriamente ditas, notamos como alguns espaço dentro das residências tais como o Butsudan (altar budista residencial) e o Tokonoma (espaço para o pergaminho e flores na sala de estudos) foram transformados em altares cristão com imagens e crucifico para o culto familiar secreto. [figura 4]

As novas igrejas (1873-1890)

Em meados do século XIX, a pressão externa começou a se tornar uma questão interna para o bakufu Tokugawa até que o Japão se reabriu para o mundo. Nagasaki que já possuía vocação para o comercio internacional desde o século XVI foi um dos primeiros portos reabertos e foi lá que um grupo de franceses da Société des Missions Étrangères de Paris começou a construir a atual Catedral Ōura para a culto dominical. ${ }^{10}$

Segundo relatos da época, logo após a uma cerimônia de dedicação em março de 1865, um grupo de japoneses da vila de Urakami vieram até à catedral e revelaram sua fé oculta para padre Petitjean dizendo: "Temos o mesmo sentimento em nossos corações que você." Evento hoje conhecido por a "Descoberta dos Cristãos" ou Shinto hakken (信徒発見), ${ }^{11}$ como escrito na base da estuada de Nossa Senhora que fica no topo das escadarias da Catedral Ōura. Razão pela qual a Catedral Ōura faz parte do Patrimônio Mundial "Sítios dos cristãos escondidos da região de Nagasaki”. Aprovado pela UNESCO em 2018.

Nos anos que se seguiram, outras comunidades de cristãos ocultos da região de Nagasaki começaram a expor sua fé e a construir suas próprias igrejas nos locais históricos associados aos eventos da época das perseguições. E hoje funcionam como repositórios da tradição imaterial dos cristãos ocultos como parte do Patrimônio da Humanidade inscrito na UNESCO.

Em termos arquitetônicos, enquanto externamente as igrejas são austeras com linhas retas, internamente foram construídas majoritariamente segundo o estilo neogótico francês. Contando com uma nave central e duas naves laterais, adornadas com arcobotantes e abóbodas ogivais. Contudo, na ausência de contrafortes externos, o peso é inteiramente direcionado para os pilares internos de madeira com capiteis em estilo corinto ou composto com cores suaves tais como branco e salmão. Ou com verniz transparente que acentua a cor original da madeira utilizada. [figuras 5 e 6] 


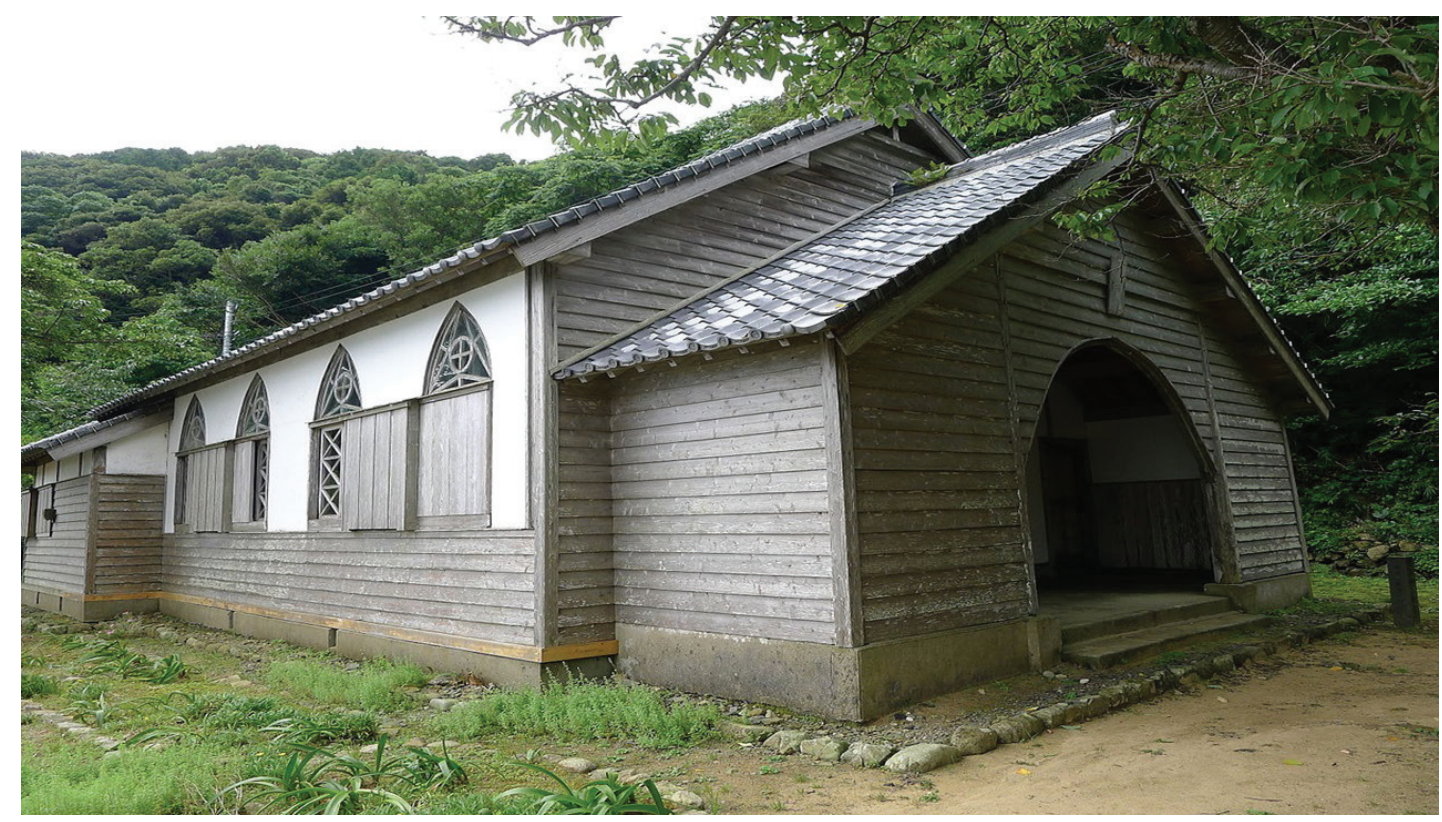

[Figura 5] Igreja de Kyuugorin. Construída em 1881 e reformada em 1931. (Fotografia externa)

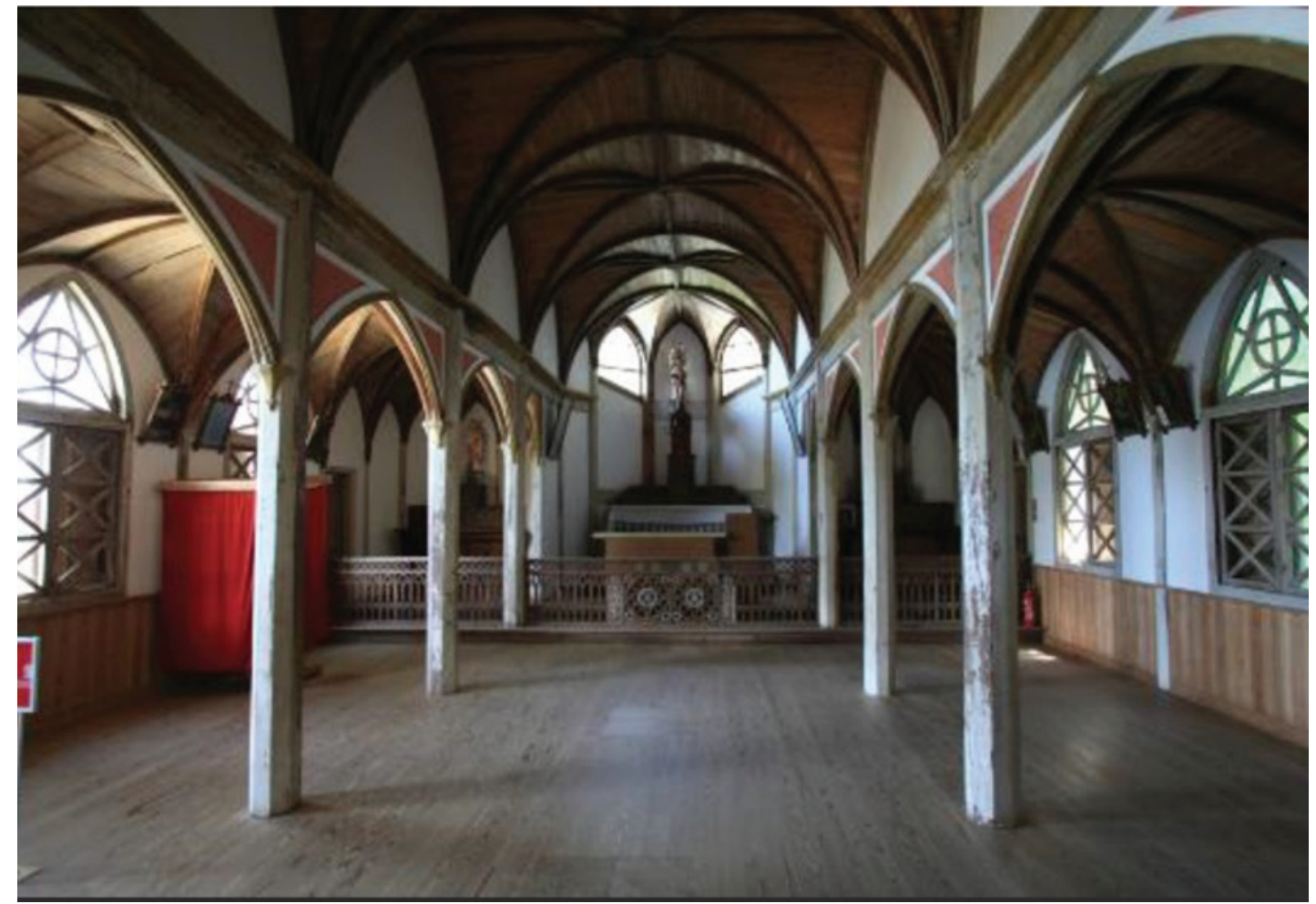

[Figura 6] Igreja de Kyuugorin. Construída em 1881 e reformada em 1931. (Fotografia interna) 
Geralmente, estas igrejas não possuíam criptas ou altares laterais, assim as imagens dos Santos e relicários estão fixados nas laterais das igrejas na parte superior onde estaria o clerestório ou no final dos corredores adjacentes. Apenas as catedrais maiores possuem abside na nave central. A ornamentação segue o cânone católico tradicional, porém combina elementos da fauna e flora japonesa atribuindo um aspecto singular as obras. Como, por exemplo, a Virgem Maria vestida em Quimono ou a representação de camélias japonesas. Os vitrais, por sua vez, geralmente são ornamentados com desenhos geométricas e o fechamento na parte superior e arquitraves são feitos na forma ogival ou em arco pleno.

As igrejas foram construídas em estruturas de madeira ou pedra e algumas delas, especialmente no interior, com teto mais baixo e tatame no lugar dos bancos. Como dita o costume local. Apesar de idealizadas por missionários europeus tais como Frs. Marmand, Fraineau, Pélu e De Rotz, ${ }^{12}$ a maioria das igrejas foram erguidas pelos mestres de carpintaria locais habituados a construção de templos religiosos tradicionais japoneses, cujo mais famoso foi Tetsukawa Yosuke ${ }^{13}$. [figuras 5 e 6] De tal modo que é possível notar algumas semelhanças entre as igrejas e templos locais nos detalhes da talha e encaixes de madeira. Na parte mais ao sul do arquipélago, os telhados das igrejas muitas das vezes seguem o estilo japonês de wagoya, enquanto na parte norte a inclinação das telhas é mais acentuada por conta da neve.

\section{Conclusão}

Ainda que sucintamente, a comunicação buscou apresentar como a arquitetura cristã no ]apão pode ser dividida em duas fases. Uma primeira entre 1549-1644 em estilo essencialmente japonês com pequenas adequações dos portugueses na busca de um "Nostrus Modus". Como por exemplo, cruz no topo do edifico, planta longitudinal e ornamentação com tríptico cristão. E um segundo momento a partir de 1873 quando se observa a inversão na proporção de partes "ocidentais" e partes "japonesas". Sendo estas novas igrejas majoritariamente ao estilo ocidental neogótico com pequenas adequações ao estilo, relevo e clima local japonês. Como por exemplo, tatame, ornamentação

\footnotetext{
12 MUNSI, 2014, p. 6-9

13 Tetsukawa Yosuke nasceu em 1897 dentro de uma família de carpinteiros e os 20 anos ele participou da construção da antiga Igreja Sone, projetada pelo pe. Pélu. Foi seu primeiro encontro com a arquitetura de estilo europeu. Ele passou a estudar com o pe. Pélu e os 27 anos projetou e supervisionou a construção da Igreja de Hiyamizu. Continuou seus estudos de arquitetura sob Frs. Fraineau e De Rotz e depois juntou-se ao Instituto de Arquitetura do Japão. Embora sendo budista toda a sua vida, ele era sensíveis ao estilo arquitetônico ocidental e foi condecorado pelo governo japonês.
} 


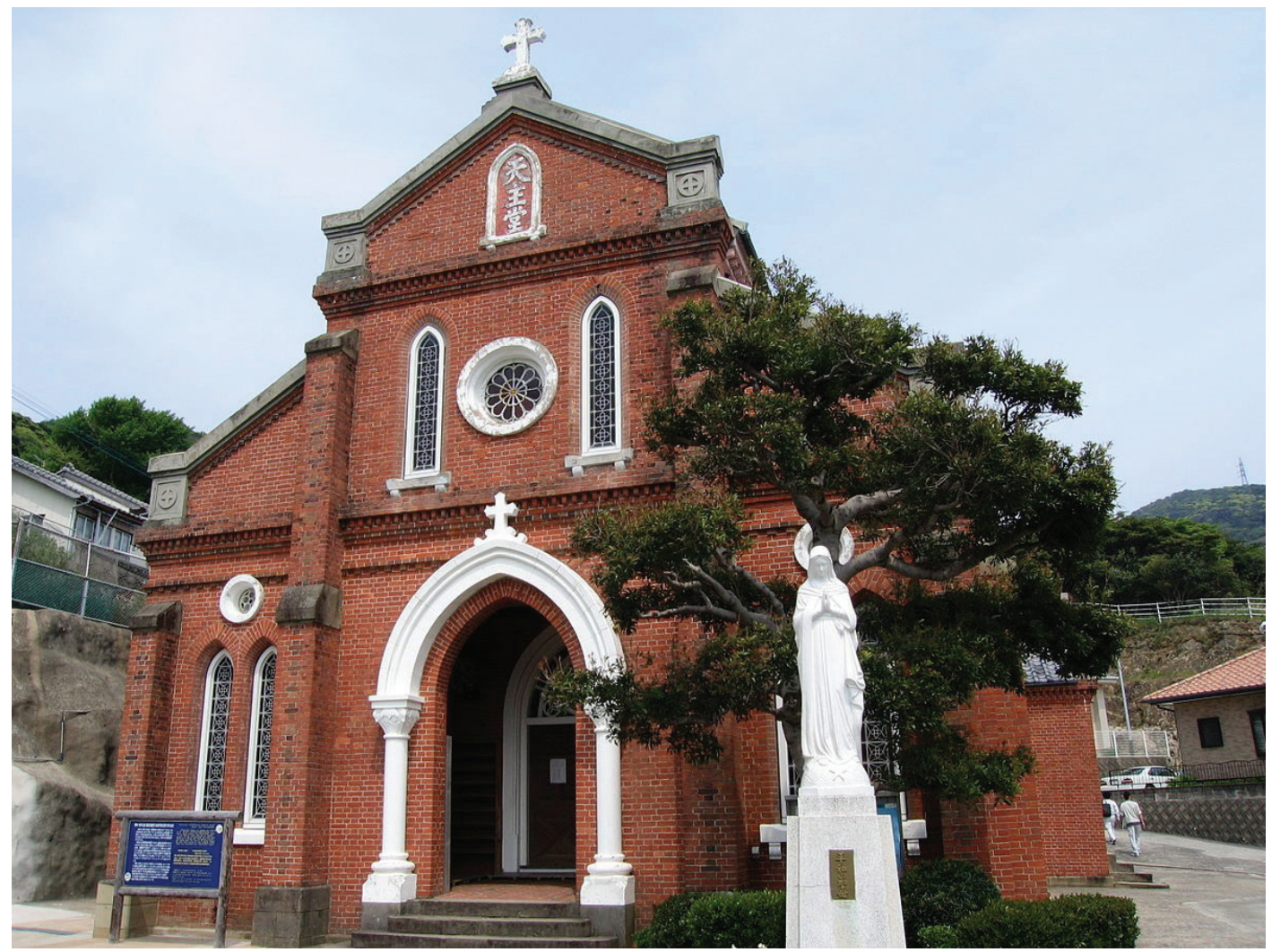

[Figura 7] Igreja de Aosagaura. Construída em 1878, e reconstruída em 1910 com projeto e supervisão de Tetsukawa Yosuke. (Fotografia externa)

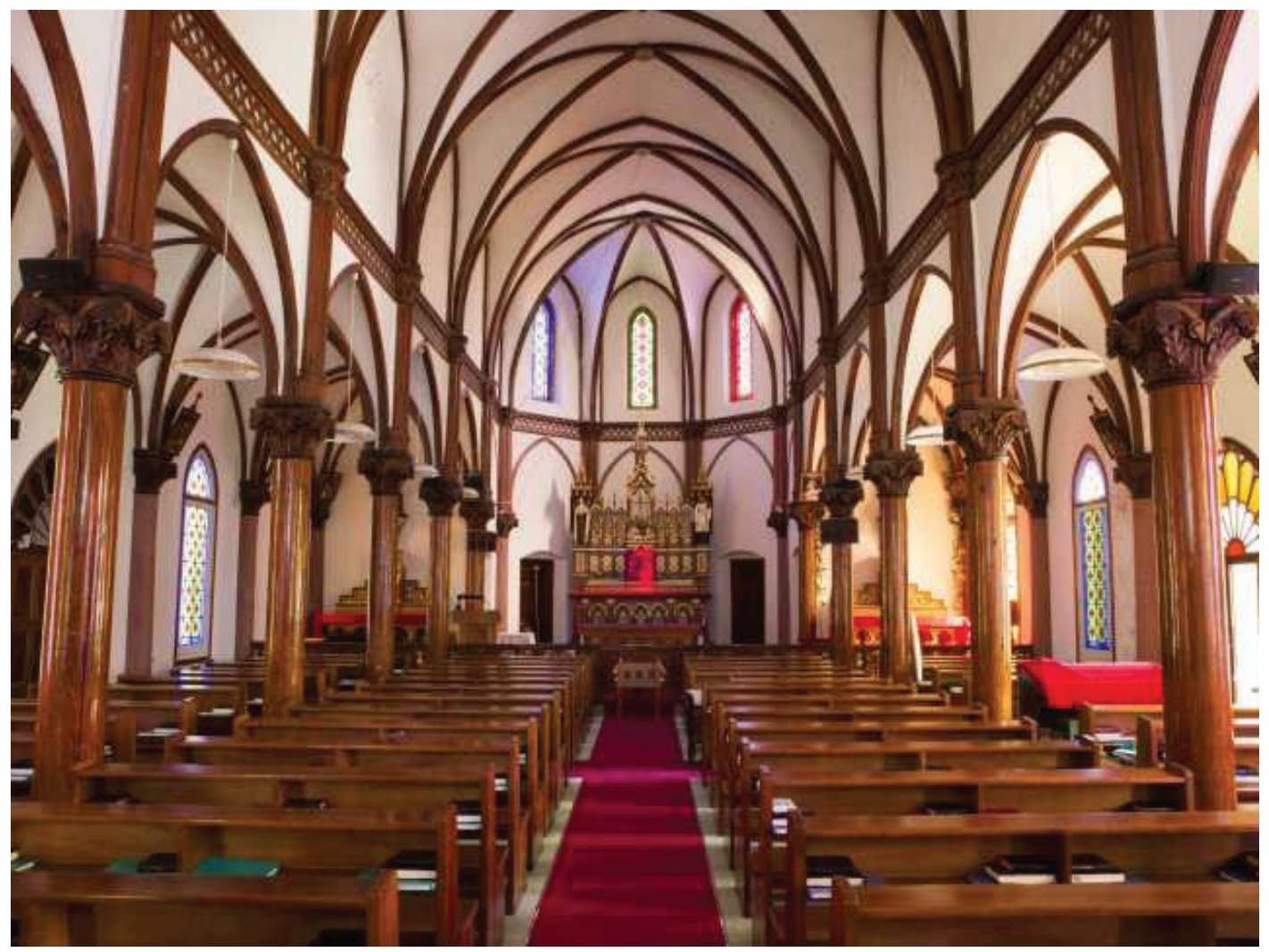

[Figura 8] Igreja de Aosagaura. Construída em 1878, e reconstruída em 1910 com projeto e supervisão de Tetsukawa Yosuke. (Fotografia interna) 
bucólica e técnicas de carpintaria e cantaria.

Todavia, como explicado pelo professor Ishikawa Tōru, é mais oportuno estudar estava evolução tipológica não como "mais ou mesmo europeia", ou "mais ou mesmo japonesa", mas sim pensando em um estilo próprio do cristianismo japonês que teve dentro de si diferenças internas ao longo da história segundo como reflexo das acondiçoes técnicas e financeiras da comunidade cristã. Na esteira deste pensamento, observa-se uma primeira fase repleta de instabilidade interna no Japão e apoio precário da Europa cuja comunidade cristã foi forçada a adaptar os templos budistas em igrejas ou construir pequenas edificações de madeira ao estilo local.

Ao passo que as edificações religiosas construídas a partir da era Meiji no século XIX foram erguidas dentro de um contexto japonês de clara ocidentalização e desenvolvimento tecnológico. Razão pela qual neste período surgiram não apenas as igrejas em estilo neogótico, mas também os primeiros edifícios públicos e bibliotecas em estilo neoclássico. E, logo em seguida, igrejas católicas e protestantes no austero estilo modernista. 


\section{Referências Bibliográficas}

ARIMURA Rie 有村 理恵. The Catholic Architecture of Early Modern Japan: Between Adaptation and Christian Identity. Japan Review, n. 27, p. 53-76, 2014

BITŌ Masahide. Thought and religion, 1550-1700. In: HALL, John W. (org.) The Cambridge History of Japan, Vol. 4. Early modern Japan, Cambridge: Cambridge University Press, p. 373-376, 2006

BOXER, Charles Ralph. Portuguese merchants and missionaries in feudal Japan, 1543-1640. Aldershot: Variorum, 1986

DINIZ, Sofia. Jesuit Buildings in China and Japan: A Comparative Study. Bulletin of Portuguese Japanese Studies, vol 3. Universidade Nova Lisboa, p. 107-128, 2001

ELISONAS, Jurgis. Christianity and the daimyō. In: HALL, John W. (org.) The Cambridge History of Japan. Vol. 4. Early modern Japan. Cambridge: Cambridge University Press, p. 301-372, 2006

HIGASHINO, Adriana Piccinini. Jesuit architecture in Japan: how to convert a Buddhist temple into a church. Anais de História de Alem-Mar, XVII, p. 245-270, 2016

KIMURA Katsuhiko 木村 勝彦. Nagasaki ni okeru Katorikku kyōkai junrei to tsūrizumu (長崎に おける カトリッ教会巡礼と ツーリズム), Nagasaki kokusaidaigaku ronsō. (長崎国際大学論叢). Nagasaki International University, vol. 7, p. 123-133, 2007

MATSUI Keisuke 松井 圭介. Seikaiisan, Nagasaki no kyōkai-gun, shūkyō-teki chiiki bunka, manazashi (世界遺産, 長崎の 教会群, 宗教的地域文化, まなざし). Tsukubadaigaku jinmonchiri-gaku kenkyu (筑波大学人文地理学研究), 31, p. 133-158, 2013

MUNSI, Roger Vanzila. Kirishitan jinja — nihondokuji no shūkyō shisetsu (キリシタン神社 — 日本独自の宗教施設). Nanzandaigaku toshokan Katorikku bunko tsūshin (南山大学図書館かトリック文庫通信), 29, p. 1-8, 2014

OLOF C. Lidin, Tanegashima: The arrival of Europe in Japan. Copenhagen: NIAS Press, 2004

SHEN, Weiwei 沈薇薇. Maria kan'non to tengusa no kakure kirishitan shinkō: Santa maria kanshozō shiryō wo chūshin ni (マリア観音と天草の隠れキリシタン信仰: サンタ・マリア館所蔵資料を中心に). Amakusashotō no bunka kōshōgakukenkyū (天草諸 島の文化交渉学研究), 2(15), p. 39-47, 2011

SHIN, Junhyoung Michael. Avalokitesvara's manifestation as the Virgin Mary: The Jesuit adaptation and the visual conflation in Japanese Catholicism after 1614. Church History, Cambridge University Press, 80(1), p. 1-39, 2011 